\title{
Review of: "Conservation of carbon resources and values on public lands: A case study from the National Wildlife Refuge System"
}

\author{
Haojie Chen ${ }^{1}$ \\ 1 Australian National University
}

Potential competing interests: The author(s) declared that no potential competing interests exist.

The study is meaningful but cannot be published until the issues below are addressed.

In Abstract, "We also used the social cost of carbon to analyze the annual benefits of sequestrating carbon...". Here, I think you should clarify what kind of social cost you're talking about (e.g., social cost of sequestering carbon using artificial approaches, or carbon emission's damage cost on society).

Section 2.2 writes: "The nested ANOVA model consisted of region". Here, please specify what "region" denotes exactly.

This study tested areas within and outside the refuges. However, it is unclear which and how many outside areas were tested and how the author selected the outside areas.

Section 2.3, there are multiple potential indicators (e.g., damage cost, cost of addressing carbon emission using artificial methods, carbon tax) of carbon sequestration. The authors should justify the indicator they used were the best available. Namely why was social damage cost, rather than other alternative indicators, used?

“The mid-range 3\% discount rate for avoiding an additional ton of CO 2 in 2018 was $\$ 48.40$ with $2.5 \%$ and $5 \%$ rates at $\$ 73.0$ and $\$ 15.0$, respectively for average climate change scenario damages". Prior this this, the non-discounted average damage cost, as well as calculation equations of net present value, should be provided to help general readers understand the methods.

Section 3.3, “Not surprisingly, refuges dominated by forest habitat generally had higher mean NECB (stronger carbon sink) than those dominated by grassland, wetland, and other habitat types". Why is this unsurprising? Please explain. I don't think forest necessarily has higher carbon sequestering abilities than other type of ecosystems.

Section 4.2. "older refuges generally store more carbon than younger ones". Please provide the best available explanation.

“The average carbon stock and average NECB are higher $(10,957 \mathrm{gCm}-2$ and $102 \mathrm{gCm}-2 \mathrm{yr}-1$, respectively) in refuges than the lands immediately outside of refuges $(9,993 \mathrm{gCm}-2$ and $85 \mathrm{gCm}-2 \mathrm{yr}-1$, respectively". Here, why? 
